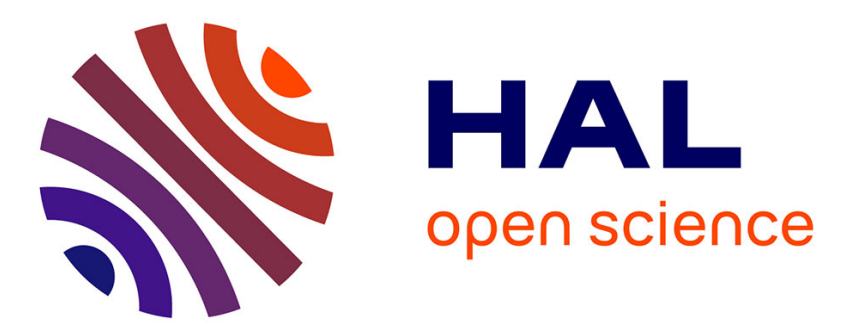

\title{
Reflections on System Properties Valued by End Users in Designing End-User Development Systems
}

\author{
Carmelo Ardito, Maria Francesca Costabile, Giuseppe Desolda, Rosa
}

Lanzilotti, Maristella Matera

\section{- To cite this version:}

Carmelo Ardito, Maria Francesca Costabile, Giuseppe Desolda, Rosa Lanzilotti, Maristella Matera. Reflections on System Properties Valued by End Users in Designing End-User Development Systems. 16th IFIP Conference on Human-Computer Interaction (INTERACT), Sep 2017, Bombay, India. pp.106-113, 10.1007/978-3-319-92081-8_10 . hal-01821412

\section{HAL Id: hal-01821412 \\ https://hal.inria.fr/hal-01821412}

Submitted on 22 Jun 2018

HAL is a multi-disciplinary open access archive for the deposit and dissemination of scientific research documents, whether they are published or not. The documents may come from teaching and research institutions in France or abroad, or from public or private research centers.
L'archive ouverte pluridisciplinaire HAL, est destinée au dépôt et à la diffusion de documents scientifiques de niveau recherche, publiés ou non, émanant des établissements d'enseignement et de recherche français ou étrangers, des laboratoires publics ou privés. 


\title{
Reflections on System Properties Valued by End Users in Designing End-User Development Systems
}

\author{
Carmelo Ardito ${ }^{1}$, Maria Francesca Costabile ${ }^{1}$, Giuseppe Desolda ${ }^{1}$, Rosa Lanzilotti ${ }^{1}$, \\ and Maristella Matera ${ }^{2}$ \\ ${ }^{1}$ Dipartimento di Informatica, Università degli Studi di Bari Aldo Moro \\ Via Orabona, 4 - 70125 - Bari, Italy \\ \{carmelo.ardito, maria.costabile, giuseppe.desolda, \\ rosa.lanzilotti\}@uniba.it \\ ${ }^{2}$ Dipartimento di Elettronica, Informazione e Bioingegneria, Politecnico di Milano \\ Piazza Leonardo da Vinci, 32 - 20134 - Milano, Italy \\ maristella.matera@polimi.it
}

\begin{abstract}
Over the years, interaction design has become increasingly complex due to the evolution of end users of interactive systems. Approaches such as usercentered design (UCD), which proved effective in the creation of usable interactive systems, have to deal with this evolution. As HCI researchers working at the design of interactive systems in several and various application domains, we are experiencing the effects of this evolution, in particular when we have to weigh up every usability aspect depending on the specific context or the target end users. In this position paper, we report our experience from the perspective of designing End-User Development (EUD) systems, i.e., software artifacts that can be modified, extended, or even created by non-professional software developers.
\end{abstract}

Keywords: User-Centred Design, Competing UI Properties

\section{Introduction}

Exponential technological advances push end users to evolve from having traditional roles as passive information consumers to more active ones. Users are increasingly willing to shape the systems they use to adapt them to their needs, tasks and habits, by manipulating and tailoring software artifacts and create new configurations or new designs. Accordingly, the goal of human-computer interaction (HCI) has been evolving from just making systems easy to use (even though that goal has not yet been completely achieved) to building frameworks that can lead to systems easy to create. This challenge is addressed by the End-User Development (EUD), an emerging paradigm that aims to empower end users to let them develop and adapt systems by themselves. A widely accepted definition of EUD is provided by Lieberman et al.: "A set of methods, techniques, and tools that allow users of software systems, who are acting as nonprofessional software developers, at some point to create, modify, or extend a software artifact" [1]. 
Enabling EUD entails providing end users, who in most cases are not technologically skilled, with appropriate environments and tools that allow them to contribute to the design, development and evolution overtime of software artifacts. Tasks that are traditionally performed by professional software developers are thus transferred to end users, who become co-designers of the tools and products they will use. This does not imply transferring the responsibility of good system design to them. It actually makes the work of professional developers even more difficult, since end users have to be supported in their new roles as designers and developers.

Building systems that permit EUD activities requires a shift in the design paradigm, which must move from user-centered and participatory design to meta-design, characterized by two main phases [2,3]. The first phase consists of creating the design environments that allow system stakeholders to participate in the design (meta-design phase). The second phase consists of the design of the final applications, carried out by the joint work of the various stakeholders, who collaborate through their design environments (design phase).

According to the meta-design paradigm, all system stakeholders, including end users, are active members of the design team. The professional developers involved in the traditional design are the team of meta-designers, who create software environments through which the other stakeholders, acting as designers, can be creative and can adapt the software to fit their specific needs. They can create and modify elements (objects, functions, user interface widgets, etc.) of the system of interest, and exchange the results of their activities to converge to a common design.

Since 2004, the researchers at the Interaction, Visualization, Usability and UX (IVU) Lab have worked on theories, methodologies, models and tools to foster the adoption of EUD systems by non-technical end users in real and various contexts such as ehealth, e-commerce, serious games, and cultural heritage (see [4] for a short description of these tools). Later, starting 2012, they have been collaborating on these topics with researchers of the Politecnico di Milano, in particular on the development of EUD platforms for web mashup [5] and smart objects configuration [6]. In the following of this paper, we describe our experience in designing an Electronic Patient Record (EPR) EUD systems in the e-Health domain and a web mashup platform that has been customized to the Cultural Heritage $(\mathrm{CH})$ and the Technology Enhanced Learning (TEL) domains.

\section{The electronic patient record case study}

The first case study refers to the medical domain. The authors collaborated with the physicians of the "Giovanni XXIII" Children Hospital of Bari, in Southern Italy, to develop some applications to support their work. In some meetings, the advantages of an Electronic Patient Record (EPR) for managing data about patient history were discussed. They clearly remarked the difficulties of accepting one of the many proposals of EPR, because they impose to practitioners predefined document templates and masks. Physicians, nurses and other operators in the medical field are reluctant to accept such unified templates; as various authors also observed [7-9], they want to customize and adapt the EPR to their specific needs. Thus, the EPR is a natural target for EUD. 
First, a contextual enquiry was carried out to study the domain, to identify and analyze the main system stakeholders, and to acquire the necessary knowledge to inform the model-based design. The following stakeholders for the EPR management were identified: 1) practice manager; 2) head physicians; 3) physicians; 4) nurses; 5) administrative staff, 6) patients. In particular, the head physician has the right and the responsibility to decide about the patient record adopted by physicians and nurses of his ward. The analysis of the work activities clearly showed that each ward personnel use their specific patient record.

Then, we created the meta-design team composed by software engineers, HCI experts and the practice manager, a domain-expert whose knowledge is necessary to design the EPR modules. The meta-design team created the software environments for the different stakeholders, as well as the data modules, which are the basic component of the EPR, and the application template to allow each head physician to design the EPR for her/his ward by directly manipulating data modules in her/his SSW. The main interface of the head physician's software environment is shown in Fig.1.

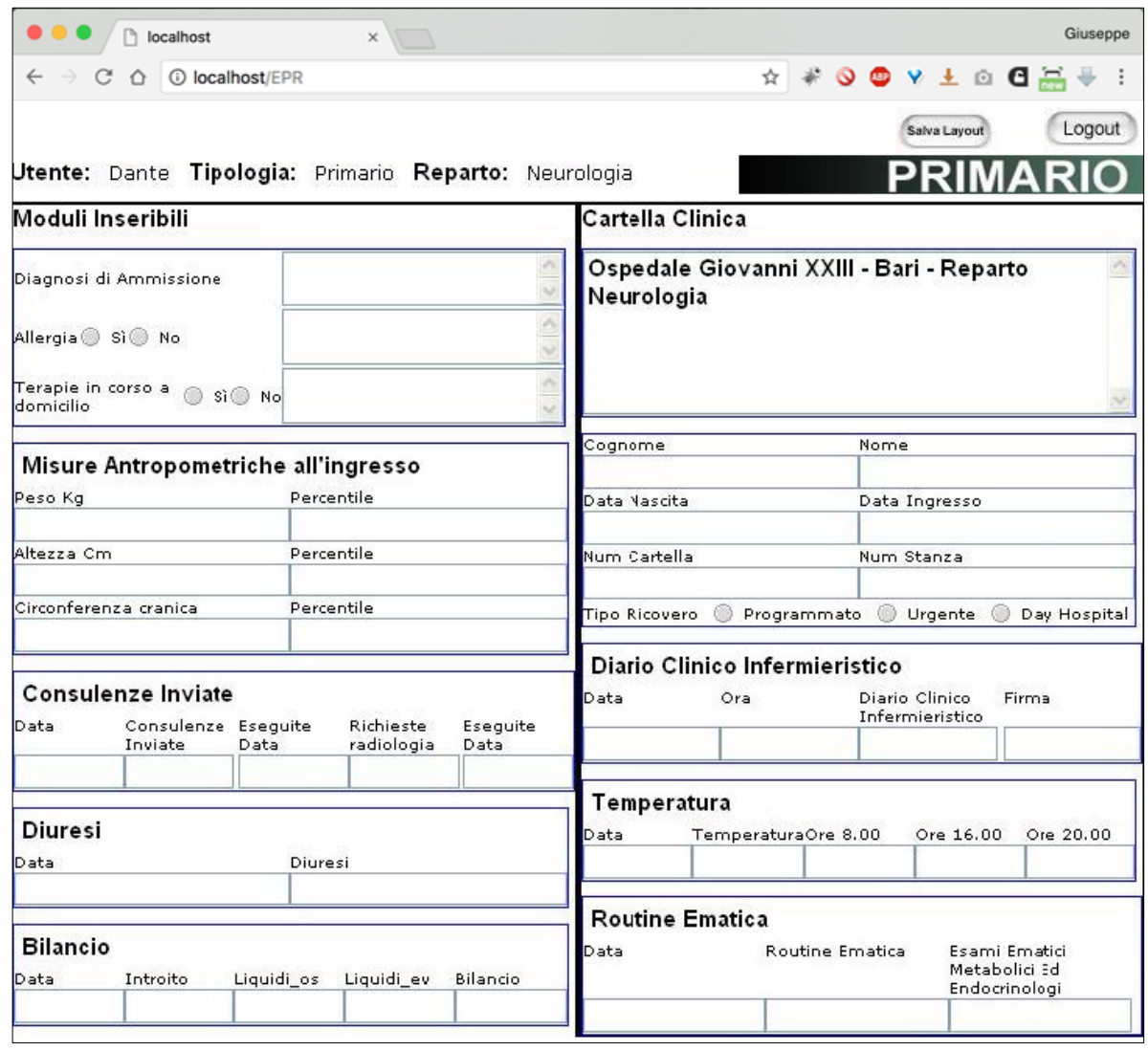

Fig. 1. Screenshot of the software environment used by the head physician for creating the EPR for the personnel in his ward by dragging the data modules from the left side to the right side 
The feedback received from the involved end users was positive and encouraging. The domain experts appreciated very much the meta-design approach, which allowed them to contribute to the design of the final applications. The head physicians the authors worked with at the hospital were never satisfied of the various proposal of EPR they had examined, which forced the adoption of a format not adequate to the needs of their wards; thus, they liked a lot the opportunity to eventually shape the EPR tailored to their wards. Another positive remark of the domain experts was that they felt to be actually aided in their designer role both by the appropriateness of the tools available in their design environment.

\section{Web mashup platform case studies}

Web mashup platforms accommodate very well EUD, as they allow end users to create new applications by integrating functions and content exposed by remote services and Web APIs [10]. We performed two field studies in different application domains, as reported in details in [11]. One study was carried out in the context of visits to archaeological parks. Two professional guides composed a mashup application for retrieving content relative to an archaeological park using a desktop application, accessible through a PC placed in their office (Fig. 2a). They associated media contents, such as photos, videos, and wiki pages with park locations to be visited during the guided tour, by searching for them on public API sources. Later, during a guided visit of the archaeological park, two guides used the mashup application to show the content to visitors by using a large interactive display when introducing the visit (Fig. 2b) and a tablet device during the tour in the park (Fig. 2c). Content was represented by a pin on a Google map centered on the park. By tapping on an icon, a pop-up window visualized the corresponding media.

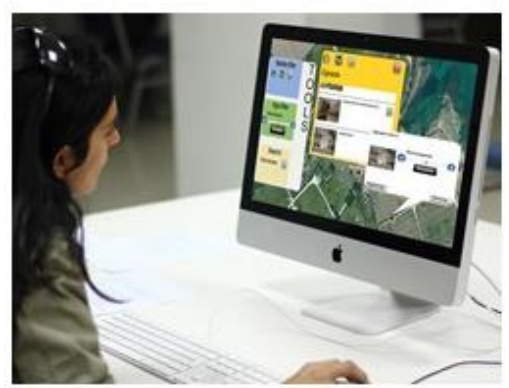

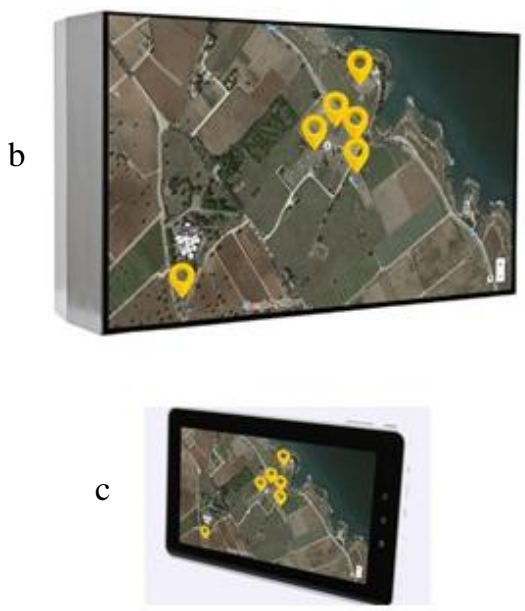

Fig. 2. A professional guide interacts with the mashup platform visualized on a PC for retrieving and organizing content on a map (a), which is later shown on a large interactive display (b) or a tablet (c) 
Another field study, performed in a context of Technology-Enhanced Learning (TEL), allowed us to analyze the use of the platform in a situation where students learn about a topic presented in class by their teacher, complementing the teacher's lecture by searching information on the Web (see Fig. 3). The retrieved information can also be communicated and shared with the teacher and the other students using interactive whiteboards, desktop PCs and personal devices (e.g., laptop, tablet and smartphone).

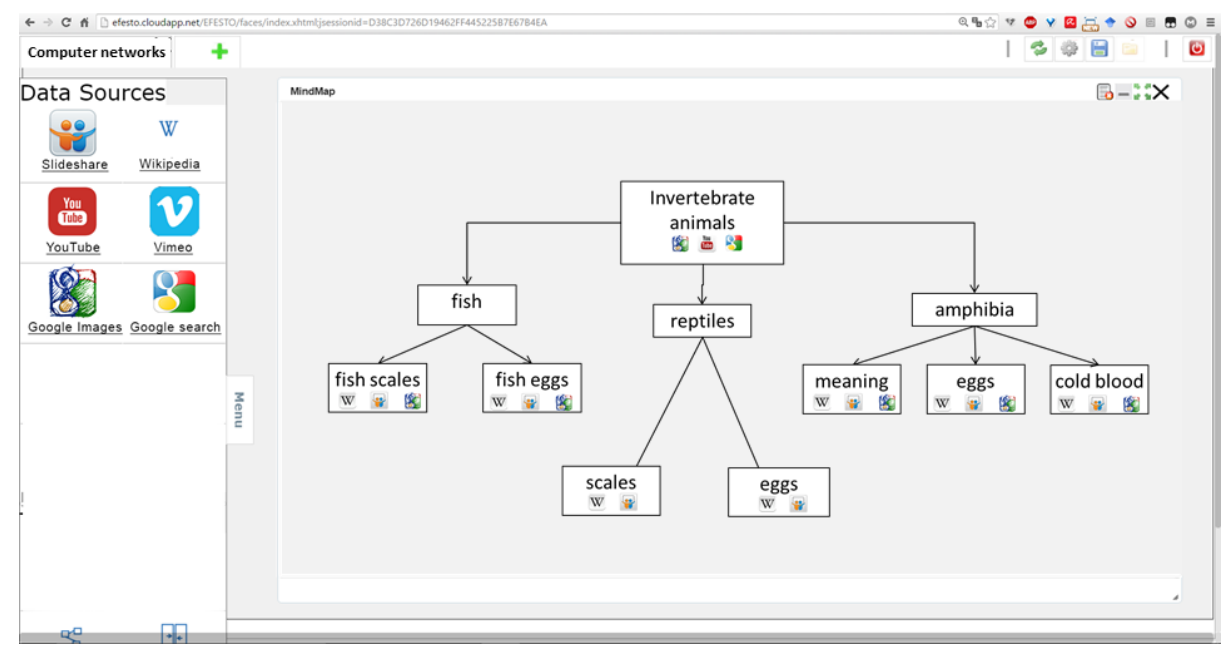

Fig. 3. A workspace on Invertebrates animals, organized as a mind map, created by the teacher using a desktop PC and later integrated by the students with further content as part of their homework.

Both the studies demonstrated that the platform is sufficiently easy to use and users felt quite supported in accomplishing their tasks. Most participants appreciated the value of the platform in enabling easy and effective integration of content retrieved on the fly from online APIs. Low response time of the platform was indicated as a negative aspect, but this was due to the very poor technology infrastructure available both at the archaeological park and at the school lab.

Participants highlighted the lack of collaboration tools, such as chats or forums. Other remarks also concerned distributed collaborative creation of components and functions to annotate services, widgets, and information items.

The studies also revealed new requirements that mashup platforms should feature to foster their adoption in real contexts. The users expressed the need to "manipulate" data extracted from services. They highlighted that through the platform they could not perform much more than visualizing data, modifying visualizations, and inspecting data details. They would instead appreciate functions to make the displayed information $a c$ tionable, i.e., suitable for being manipulated according to their task goals [12]. For example, in the content retrieval task, beyond composing services and choosing how to visualize retrieved content, participants also wanted to perform ordering, filtering, or selecting a specific part of a content item, possibly annotating the selected parts with comments. Another important requirement that emerged is related to the information 
retrieval power of the mashup platforms: users reported that, in order to satisfy complex information needs, data should be gathered from the entire Web - not only from web service APIs.

\section{Discussion and Conclusion}

EUD has started the trend toward a more active involvement of end users in the overall software design, development, and evolution processes, to allow them becoming codesigners of the tools and products they will use. The studies showed that the users of EUD tools are focused on aspects related to the effectiveness in supporting the tasks they are performing and the customizability of the system in respect to the their tasks. Therefore, other system properties come into play. One is the system flexibility, an ingredient that can be favored by the identification of elementary components that can then be assembled together to give life to brand new interactive systems. In this case, the focus on usability is more related to the composition paradigm offered to the end users than to the final interactive applications the end users build by themselves.

In the specific context of the mashup platform, in which the overarching goal was information retrieval, end users also considered important other factors such as quality, completeness and trust of the retrieved data [13], as well as peer communication, sharing and annotating features. Nobody considered other attributes related to aesthetic, graphic aspect, security, privacy. The results of previous evaluations of EUD tools, applied in different application domains and based on various technologies (e.g., electronic patient records, e-commerce websites, cultural heritage authoring tools), also confirm that end users consider important the capability of their own tools to support them in hitting their goal.

This analysis suggests that in this new process the responsibility of good system design cannot be transferred to end users, who have to be assisted by other ICT professional stakeholders in this new role of designers and developers. This actually makes the work of professional developers even more difficult, since: a) it is still their responsibility to ensure the quality of the software artifacts created by end users [14], and b) they have to create proper tools that support end users in this new role. In order to address these issues, our methodology for designing EUD systems is based on a metadesign model. Differently than in traditional design, professional developers do not directly create a final application, but they build software environments thorough which non-technical end users, acting as co-designers, are enabled to shape up the application they are going to use.

Another issue, which emerged in the field studies that we have conducted to validate our tools, is that some problems occur when the proposed EUD systems are too "general", claiming that one single design might satisfy the requirements of many domains. We therefore proposed domain customization as a solution to make meta-design still more effective in creating platforms that really fit the end-user needs [15]. For example, in the case of the mashup platform experiences, customization occurs by selecting and registering into the platform services and data sources (public or private) that, for any different domain, can provide content able to fulfill specific users' information needs. 
Service registration is kept as simple as possible, so that even non-technical users can possibly add new services if needed.

Our current research is focused on designing EUD systems for the configuration of smart objects by non-technical users [16]. As future work in the direction of investigating which system properties are valued by EUD-system users, we will exploit this new application domain to address issues such as how our meta-design and customization approach can be possibly modified in order to manage competing properties. In particular, we want to revise the role of the HCI expert, already included in the meta-design team, so that he/she can be empowered in providing guidance and feedback to end users when they act as designers.

Acknowledgments. This work is partially funded by the Italian project SHELL (Shared Interoperable Home Ecosystems for a Green, ComfortabLe and Safe Living - CTN01 00128 111357) and by the project COSMOS (Creation Of SMart spaces fOr end-uSer empowerment) funded by the University of Bari Aldo Moro.

\section{$5 \quad$ References}

1. Lieberman, H., Paternò, F., Klann, M., Wulf, V.: End-User Development: An Emerging Paradigm. In: Lieberman, H., Paternò, F., Wulf, V. (eds.), End User Development, pp. 1-8. Springer Netherlands, Dordrecht (2006)

2. Costabile, M.F., Fogli, D., Mussio, P., Piccinno, A.: Visual Interactive Systems for EndUser Development: A Model-Based Design Methodology. IEEE Transactions on Systems, Man, and Cybernetics - Part A: Systems and Humans 37(6), pp. 1029-1046 (2007)

3. Fischer, G., Giaccardi, E., Ye, Y., Sutcliffe, A., Mehandjiev, N.: Meta-design: a manifesto for end-user development. Communications of the ACM 47(9), pp. 33-37 (2004)

4. Ardito, C., Buono, P., Costabile, M.F., Lanzilotti, R., Piccinno, A.: End users as codesigners of their own tools and products. Journal of Visual Languages \& Computing 23(2), pp. 78-90 (2012)

5. Ardito, C., Costabile, M.F., Desolda, G., Lanzilotti, R., Matera, M., Piccinno, A., Picozzi, M.: User-driven visual composition of service-based interactive spaces. Journal of Visual Languages \& Computing 25(4), pp. 278-296 (2014)

6. Ardito, C., Costabile, M.F., De Angeli, A., Lanzilotti, R.: Enriching exploration of archaeological parks with mobile technology. ACM Trans. Comput.-Hum. Interact. 19(4), Article 29, pp. 1-30 (2012)

7. Morrison, C., Blackwell, A.: Observing End-User Customisation of Electronic Patient Records. In: Pipek, V., Rosson, M.B., de Ruyter, B., Wulf, V. (eds.), End-User Development. Vol. 5435, pp. 275-284. Springer, Berlin / Heidelberg (2009)

8. Cabitza, F., Simone, C.: WOAD: A Framework to Enable the End-User Development of Coordination-Oriented Functionalities. Journal of Organizational and End User Computing, pp. 1-20 (2010)

9. Cabitza, F., Gesso, I., Corna, S.: Tailorable flexibility: Making end-users autonomous in the design of active interfaces. In: IADIS Multi Conference on Computer Science and 
Information Systems (Tailorable flexibility: Making end-users autonomous in the design of active interfaces), Rome, Italy. pp. 53-60 (2011)

10. Daniel, F., Matera, M.: Mashups - Concepts, Models and Architectures. Springer (2014)

11. Ardito, C., Bottoni, P., Costabile, M.F., Desolda, G., Matera, M., Picozzi, M.: Creation and Use of Service-based Distributed Interactive Workspaces. Journal of Visual Languages \& Computing 25(6), pp. 717-726 (2014)

12. Ardito, C., Costabile, M.F., Desolda, G., Latzina, M., Matera, M.: Making mashups actionable through elastic design principles. In: Díaz, P., Pipek, V., Ardito, C., Jensen, C., Aedo, I., Boden, A. (eds.), End-User Development - IS-EUD 2015. Vol. LNCS 9083, pp. 236-241. Springer, Berlin Heidelberg (2015)

13. Cappiello, C., Daniel, F., Matera, M., Pautasso, C.: Information Quality in Mashups. IEEE Internet Computing 14(4), pp. 14-22 (2010)

14. Ko, A.J., Abraham, R., Beckwith, L., Blackwell, A., Burnett, M., Erwig, M., Scaffidi, C., Lawrance, J., Lieberman, H., Myers, B., Rosson, M.B., Rothermel, G., Shaw, M., Wiedenbeck, S.: The state of the art in end-user software engineering. ACM Comput. Surv. 43(3), pp. 1-44 (2011)

15. Ardito, C., Costabile, M.F., Desolda, G., Matera, M.: A Three-Layer Meta-Design Model for Addressing Domain-Specific Customizations. In: Paternò, F., Wulf, V. (eds.), New Perspectives in End-User Development, pp. 99-120. Springer International Publishing, Cham (2017)

16. Desolda, G., Ardito, C., Matera, M.: Empowering End Users to Customize their Smart Environments: Model, Composition Paradigms, and Domain-Specific Tools. ACM Trans. Comput.-Hum. Interact. 24(2), pp. 1-52 (2017) 